\title{
A HISTÓRIA NAS ESTÓRIAS DAS MULHERES DO RAJ
}

\author{
Cielo G. Festino* \\ Doutoranda em Letras Modernas - FFLCH/USP
}

\section{Resumo}

Nosso artigo tem como intuito mostrar a centralidade da literatura das mulheres do Raj durante a presença do império britânico no subcontinente indiano. Com esse propósito analisaremos três contos, escritos entre o fim do século XIX e início do século XX, para mostrar como essas escritoras vão além dos limites da ficção do pitoresco, o local epistmológico a que elas são relegadas pelo discurso imperial, para expressar a sua visão da história colonial.

\section{Pallavras-Chave}

História • Estória • Pitoresco • Anedota • Hermenêutica do Cotidiano

\section{Abstract}

In this article we propose to discuss the relevance of the literature written by the women of the Raj during the time of the English Empire on the Indian subcontinent. Therefore we will interpret three short stories written at the end of the nineteenth and beginning of the twentieth century to show how these women writers go beyond the 'literature of the pictureseque', the epistemological locus in which they are imprisoned by imperial discourse, in order to express their own views on colonial history.

\section{Keywords}

History $\bullet$ Fiction $\bullet$ Picturesque $\bullet$ Anecdote $\bullet$ Hermeneutics of everyday life

\footnotetext{
* Bolsista do CNPq.
} 


\section{Introdução}

O propósito do presente artigo é elaborar uma releitura de textos literários escritos pelas mulheres do Raj (governo imperial inglês na Índia) com o intuito de mostrar como, embora reduzidos ao pitoresco, o anedótico e o cotidiano são centrais no projeto da história colonial. Essas narrativas pertencem à tradição literária "anglo-indiana", ou seja, a literatura inglesa sobre a Índia escrita principalmente pelos oficiais coloniais ingleses, suas mulheres, viajantes e demais ingleses residentes no sub-continente, na segunda metade do século XIX e primera metade do século XX.

Segundo Jacques Derrida, o conceito do suplemento carrega em si mesmo duas significações. Por um lado, o suplemento se acrescenta a si mesmo; é um excedente, uma plenitude que enriquece uma outra plenitude mas, por outro lado, o suplemento se acrescenta para substituir, se insinua no "lugar de". Se prencheer, é como preencher um vazio. Se representar e fizer uma imagem, é pela omissão de uma presença (1992:83).

Entendemos que esse segundo caráter do suplemento, segundo a definição de Jacques Derrida, se aplica às narrativas das escritoras do Raj porque, embora pensadas como apêndice do discurso histórico colonial masculino no sentido de que simplesmente acrescentam algo a um original, esses textos fornecem uma visão aguda do choque cultural que teve lugar nesses anos entre ingleses e indianos, a ponto de poderem ser entendidos como plenitude ou presença em justaposição ao discurso sendo suplementado (Menezes de Souza 1994:61). Assim, essas narrativas femininas parecem superar, implicitamente, nas palavras de Maria Odila Leite da Silva Dias, "as polaridades tanto das relações de gênero como das categorias de pensamento" que lhes são impostas (1994:373). No primeiro caso porque, embora limitadas ao plano do ficcional e, por isso, entendidas como simples gesto estético, são testemunhas da história de contato que se gerou a partir do encontro entre colonizador e colonizado e, no segundo caso, devido a este fenômeno, elas também pertencem ao marco das narrativas da história colonial.

Segundo nossa leitura, quanto mais as autoras tentam reduzir o narrado a um gesto pitoresco, como que obedecendo à epistemologia imperial, mais se destaca a consciência da importância histórica daquilo que está sendo contado e fica mais claro que é nas entrelinhas da estória que a história é narrada. Lemos essas estórias/histórias, então, como carregadas de “....sentidos implícitos, à margem do normativo e do institucional, que podem ser vislumbrados nas entrelinhas, ou nos intervalos intertextuais, de certa forma sempre subversivos da ordem, do permanente, cuja existência negam" (Silva Dias 1994:377). 
Ao mesmo tempo, essas narrativas de estilo oblíquo e impregnadas de silêncio em seu desejo de auto-redução à linguagem do decoro (característica da literatura vitoriana do século XIX e conveniente ao discurso colonial) falam também, de maneira eloqüente, não só do confinamento da mulher inglesa dentro dos limites do cantonment, o exclusivo distrito dos britânicos nas cidades da Índia, mas também das próprias narrativas ditas pitorescas.

Segundo apontado, essas estórias foram escritas durante a segunda metade do século XIX e a primeira metade do século XX, momento significativo das narrativas inglesas sobre a Índia, porque nessa época a resistência indiana ao imperialismo britânico foi muito intensa e organizada devido à formação do Movimento Nacionalista Indiano pela Independência, o que por sua vez representou uma grande ameaça para o governo britânico na Índia. O que isto produziu foi uma narrativa ainda mais articulada por parte dos britânicos sobre a importância da sua presença no subcontinente (Hubel 1996:2). É com esse pano de fundo que as mulheres escritoras que estudaremos a seguir constroem seus textos.

Para mostrar então como o discurso da história, associado com o real, é sufocado nessas estórias, consideraremos primeiramente a redução da Índia ao exótico como parte da missão civilizatória dos ingleses no subcontinente em "Lâl" (1894) de Flora Annie Steel; a recriação dos temas das narrativas mestres da história colonial, como o Amotinamento de 1857, através do anedótico em "Ann White" (1901) de Alice Perrin e o estudo da "hermenêutica do cotidiano" (Silva Dias 1994), segundo apresentado em "Uma mãe na Índia" ("A Mother in India") (1903) de Sara Jeannete Duncan. Enquanto as duas primeiras escritoras mencionadas são inglesas, Sara Jeannette Duncan é canadense. Porém incluímos a sua narrativa porque entendemos que, embora de outra colônia do império, os colonos originários da Inglaterra que moravam no Canadá se acreditavam brancos e ingleses e, portanto, diferentes dos outros nativos.

Como marco teórico, consideraremos os artigos "O pitoresco feminino" ("The Feminine Picturesque") (1992) da crítica paquistanense Sara Suleri, "Novas subjetividades na pesquisa histórica feminista: uma hermenêutica das diferenças" (1994) da historiadora brasileira Maria Odila Leite da Silva Dias, assim como os estudos sobre escritores do Raj de Benita Parry (1972), Teresa Hubel (1996) e Patrick Brantlinger (1988). 


\section{Relendo as narrativas femininas do Raj}

No seu livro A retórica da Índia inglesa (1992), Sara Suleri explica que nas narrativas das mulheres inglesas na Índia, sua responsabilidade social estaria limitada a reafirmar a qualidade do pitoresco na imagem do Outro indiano. Suleri acrescenta que, como etnógrafas amadoras, as mulheres podiam “... desenhar a paisagem ou representar fisonomias. Porém, elas tinham que se manter alheias a qualquer conclusão sociológica de seus própios dados. Elas podiam se aventurar no terreno do político com um interesse estético, mas nunca para analisá-lo ${ }^{1}$ " (1992:74). Então, nas narrativas literárias femininas, como contos e romances, o nativo e a vida na Índia são domesticados em imagens que pretendem refletir a visão aceita e garantida pelo Raj.

Mas toda representação textual é uma construção de significados, já que ela é, em si mesma, uma forma de interpretação daquilo que está sendo narrado. Então o olhar etnográfico das inglesas, embora amador e tentando se restringir ao estético, implica uma criação do Outro em que o posicionamento ideológico nunca se separa do elemento estético. Aliás, como aponta Bakhtin (1981), uma das características da linguagem é o seu caráter heteroglóssico, já que as palavras nos precedem e são carregadas de significados, além daqueles que queremos imprimir através da nossa ilusão de agência. Assim, as estórias/histórias aqui analisadas, ao mesmo tempo em que querem guardar seu lugar periférico no discurso imperial, denunciam não só a visão histórica das mulheres, que tanto pode reafirmar como contradizer o olhar masculino, mas também o próprio sentido de confinamento em uma estrutura social da qual elas nunca dizem abertamente serem vítimas. Em outro nível, essa tensão entre o dito e o nãodito vem demonstrar a repressão da mulher no discurso colonial e, ao mesmo tempo, segundo o conceito de Silva Dias (1994), o seu desejo de subvertê-lo indo além dos papéis normativos que lhes são impostos.

\footnotetext{
${ }^{1}$ Nossa tradução.

${ }^{2}$ Flora Annie Steel escreveu romances dentre os quais se destacam The Potter's Thumb (1894), On the Face of the Waters (1896), e coletâneas de contos como From the Five Rivers (1893), The Flower of Forgiveness (1894), In the Permanent Way and Other Stories (1898) e In the Guardianship of God (1903).
} 


\section{II.1 "Lâl": além dos limites do pitoresco}

Flora Annie Steel (1847-1929) foi uma das escritoras mais prolíferas do $\mathrm{Raj}^{2}$. Como os oficiais britânicos, ela também sentia que conhecia de perto a cultura indiana, não só pelo fato de morar na Índia mas porque, junto com o seu marido, muitas vezes esteve em postos militares britânicos onde eles eram os únicos brancos. Ela ajudou nas escolas, ensinou inglês e também aprendeu línguas locais.

Segundo a crítica Benita Parry, sua existência na Índia foi menos vicária em relação à de outras mulheres inglesas. Porém, Steel escreveu na sua autobiografia que o fato de conhecer as línguas dos indianos e estudar os seus hábitos e costumes, era a melhor maneira de os controlar, o que significa que seu desejo não era conhecê-los mas sim manter o seu lugar de poder. Ao mesmo tempo, Parry explica que para Steel, quando o homem branco faz parte do contexto indiano, defronta-se com costumes tão primitivos que, se ele não tentar manter certos limites, poderá perder sua equanimidade e o respeito do nativo como senhor. Então, para Steel, conhecer o colonizado significa digerir aquela informação que será útil para melhor governá-lo. Essa ideologia vai se refletir em sua literatura, numa leitura da Índia que claramente vai além dos limites do pitoresco.

Assim, os eventos que Steel narra nas suas estórias e romances são apresentados de tal maneira que a vida do indiano, na terminologia de Homi Bhabha (1992), é narrada como uma contingência no fluir da experiência britânica na Índia, porque mais do que tentar contar a estória/história do Outro, nos seus próprios termos, a autora está preocupada com o seu lugar de enunciação como uma maneira de reafirmar a identidade inglesa e justificar a sua presença num local onde se sabe ser invasora.

Assim, embora "Lâl", o conto que estudaremos a seguir, faça parte do seu livro Tales from the Punjab (1894), a Índia continua sendo a grande personagem ausente porque para Steel é quase que impossível resignificar a vida do indiano a partir dos seus próprios códigos sociais, uma vez que sua missão civilizatória ignora as diferenças culturais, devido ao seu desejo de se auto-impor. Nas palavras de Suleri, "A Índia é aquele local ausente que as narrativas anglo-indianas do século dezenove tentam representar mas que nunca podem possuir. Nesse processo, as identidades nacionais e culturais desaparecem no vazio da representação"3 (1992: 48).

\footnotetext{
${ }^{3}$ Nossa tradução.
} 
Em "Lâl" essa idéia está contida no subtexto da narrativa. A estória trata das experiências de um funcionário da administração do império na Índia numa de suas viagens de reconhecimento do subcontinente, com o objetivo de marcar a área fértil do rio Hindus e, assim, "racionalizar" os cultivos segundo os padrões ingleses. Seu desejo de impor sua própria lógica não se reduz à geografia, mas se faz extensivo às comunidades de camponeses indianos com os quais ele se defronta.

O que é significativo na narrativa de Steel é o fato de ela escolher um narrador masculino e não feminino. Entendemos que isso se deve ao fato de ela estar ciente de que sua narrativa vai se concentrar em um tipo de experiência que vai além do limite do pitoresco e, por isso, é privativa dos homens, já que só eles podiam se aventurar em lugares longínquos. Então, por um lado, ela se constrói como sujeito narrador colocando-se atrás do olhar masculino, com a pretensão de se restringir ao lugar designado à mulher ao mesmo tempo em que, por outro lado, ela subverte esse locus de enunciação para se pronunciar sobre a história colonial, paradoxalmente, segundo a visão feminina.

Nessa viagem, o narrador se defronta com uma personagem lendária chamada "Lâl" que é apresentada como parte do mistério que os ingleses associam à Índia:

Quem era Lâl? O que era ele? Essa era uma pergunta que eu fazia muitas vezes: e embora ela fosse devidamente respondida, Lâl permanecia, e permanece ainda, uma quantidade desconhecida - uma abstração, um nome e nada mais. LAL. O mesmo de frente para trás, contido em si mesmo, auto-suficiente $(51)^{4}$

Embora aceitando que seu questionamento tenha sido respondido, o narrador segue com a mesma interrogação do princípio: ele não pode entender as palavras dos indianos porque sempre tenta decodificá-las segundo seus próprios parâmetros culturais. A pergunta que o narrador de Steel coloca reforçaria, por um lado, o grande desconhecimento que os ingleses tinham do subcontinente já que, para ele, Lâl tanto pode ser um objeto como uma pessoa,

\footnotetext{
4 "Who was Lâl? What was he? This was a question I asked many times; and though it was duly answered, Lâl remained and remains still, an unknown quantity - an abstraction, a name and nothing more. LAL. The same backwards and forwards, self-contained, self-sufficing".
} 
indiretamente mostrando como, para os ingleses, os indianos, mais que humanos, seriam parte da geografia. Por outro lado a pergunta mostraria o seu desejo de controle ao tentar reduzir o Outro ao seu próprio discurso. Assim, a narrativa se estrutura a partir da pergunta e não da resposta. Por sua vez, o que se lê nas palavras do indiano, além da intencionalidade da autora, é sua maneira pacífica de resistir: "Ora, Lâl era Lâl” $(53)^{5}$, porque a Índia era a Índia e para eles, indianos, a sua própria cultura estava além de toda explicação.

Mas o narrador insiste com a mesma categoria de perguntas que, uma vez mais, falam mais do contexto de enunciação de onde elas foram formuladas do que do desejo de tentar se comunicar com o Outro. A próxima passagem do texto mostra o questionamento ainda mais longe do indiano quando o inglês tenta medir o desconhecido em termos de impostos, o seu verdadeiro interesse:

Detido pela minha curiosidade, refugiei-me nos negócios perguntando que impostos Lâl pagava em seu campo. Isso foi demais para a gravidade educada dos meus ouvintes. A idéia de Lâl pagando impostos era evidentemente irresistivelmente cômica, e o venerável bufão se engasgou entre uma tossida e uma risada, pedindo para ser erguido e levar uns tapinhas nas costas $(54)^{6}$.

Interpretamos o fato de o inglês tentar reduzir a cultura do Outro, neste caso representada por Lâl, segundo a sua própria racionalidade, como uma manifestação do medo do colonizador, sempre latente no contato com o Outro, de ser contaminado pela cultura local e assim enfraquecer o seu local de poder. Conforme já apontamos anteriormente, nesse contexto, aquilo que resiste ao impulso de tradução cultural do colonizador é reduzido a uma contingência. Segundo a teoria de Menezes de $\mathrm{Souza}^{7}$, isso vem demonstrar que há um grande desejo na

\footnotetext{
5 "Why Lâl was Lâl".

6 "Baulked in my curiosity, I took refuge in business by inquiring what revenue Lâl paid on his field. This was too much for the polite gravity of my hearers. The idea of Lâl paying revenue was evidently irresistibly comic, and the venerable pantaloon choked himself between a cough and a laugh, requiring to be held up and patted on the back".

${ }^{7} \mathrm{O}$ tema da relação entre símbolo e signo foi um tema desenvolvido pelo Prof. Dr Lynn Mario T. Menezes de Souza no curso de pós-graduação "Identidade e Narrativa" ministrado no Departamento de Letras Modernas da Universidade de São Paulo no segundo semestre de 2002.
} 
literatura colonial de domesticar a cultura do Outro apresentando-a como símbolo e não como signo no sentido de não tentar resignificar esses costumes considerados exóticos. Isto é, reconsiderar o significante, em termos do seu contexto cultural, o significado que lhe é conferido pela própria comunidade.

Então, quando a cultura do Outro não se encaixa nos parâmetros racionais do colonizador, ela é obliterada ou reduzida a um mistério: "Há tantos mistérios na vida camponesa indiana, seguramente escondidos dos olhos alheios, que eu me contentava preguiçosamente em deixar Lâl e seu campo cair no limbo das coisas não inteiramente compreendidas e, então, logo eu me esqueci completamente dele" $(54)^{8}$.

O que se vê pelas fissuras da estória é o que a autora, através de seu narrador, conta sobre a história do encontro/desencontro entre colonizador e colonizado. E assim temos, por um lado, a falta de interesse do colonizador em conhecer a cultura do Outro e, pelo outro, a resistência do colonizado por meio de um discurso propositalmente irônico, carregado de silêncios e enigmas já que, enquanto o narrador tenta fixá-lo num estereótipo, as suas respostas, que o colonizador considera como infantis ou simplórias, representam seu 106 modo de resistência a um desejo de controle.

Como já for apontado, uma das características da literatura feminina seria a suposta pretensão de se manter neutra com relação ao narrado, nas margens dos textos históricos do projeto colonial. Assim como nas narrativas de viagem, a maior parte de "Lâl" tem a ver com a descrição da paisagem através de um texto aditivo de coordenação, mais do que um texto explicativo de subordinação. O primeiro estilo discursivo se restringiria a uma simples enumeração de tudo aquilo que o narrador enxerga, num desejo (caso fosse possível) de representação mimética da realidade na qual a interpretação do narrador está ausente. $\mathrm{O}$ segundo modo, ao estabelecer uma hierarquia entre os termos representados, implicaria um posicionamento critico com respeito ao que está sendo narrado:

\footnotetext{
8 "There are so many mysteries in Indian peasant life, safe hidden from alien eyes, that I was lazily content to let Lâl and his field slip into limbo of things not thoroughly understood, and so, ere long, I forgot all about him."
} 
Assim, de uma cena de perda ou ganho para outra, enquanto o sol brilhava no céu claro. Por poças de água cristalina onde garças-azuis de bico vermelho se equilibravam sobre uma perna, como se sentissem frio no ar revigorante da manhã. Nos trechos desertos de areia onde córregos límpidos e bandos de garças brancas combinavam para formar um bordado prateado na imensidão marron. Por sobre o vau raso onde jacarés narigudos entravam silenciosamente no córrego, ou ficavam imóveis como sombras na areia escaldada pelo sol. Descendo o grande rio, onde a água sinuosa se partia para a esquerda ou direita, e onde os anciãos deitavam na água seus potes de barro para decidir qual dos dois córregos iria provar sua força levando o maior número deles - uma questão de peso, não facilmente resolvida, uma vez que a terra à oeste do grande córrego pertencia a um vilarejo, e a terra à leste pertencia a outro $(52)^{9}$.

Nessa geografia detalhadamente explicada em termos de advérbios de lugar, onde o tempo não parece transcorrer, a Índia aparece como que estagnada através dos séculos, enquanto o indiano se confunde com as características estáticas da paisagem, não tendo, assim, nem nome nem fisionomia clara.

A obliteração do cronotopo ${ }^{10}$ do indiano na narrativa de Steel responde ao que Sara Suleri chama de "uma estética amorfa", na qual o nativo é reduzido a um tempo que claramente difere daquele do narrador. Nesse contexto, a cultura da Índia é apresentada de maneira sincrônica, segundo a qual o indiano vive num estágio do passado anterior ao do colonizador, enquanto este, sujeito

\footnotetext{
9 "So from one scene of loss or gain to another, while the sun shone in the cloudless sky overhead. Past pools of shining water where red-billed cranes stood huddled up on one leg, as if they felt cold in the crisp morning air. Out on the bare stretches of sand where glittering streams and flocks of white egrets combined to form a silver embroidery on the brown expanse. Over the shallow ford where the bottle-nosed alligators slipped silently into the stream, or lay still as shadows on the sun-baked sand. Down by the big river, where the swirling water parted right and left, and where the grey-beards set their earthen pots a-swimming to decide which of the two streams would provide its strength by bearing away the greater number, -a weighty question, not lightly decided since the land to the west of the big stream belonged to one village, and the land eastward to another".

${ }^{10}$ Mikhail Bakhtin (1981:425) define o "cronotopo" como uma unidade de análise para estudar a natureza das categorias temporais e espaciais representadas nos textos. A diferença desse conceito com outros usos de tempo e espaço na análise literária encontra-se no fato de que nestes ambas categorias são interdependentes e, portanto, nehuma delas é privilegiada.
} 
cartesiano, vive entre o presente e o futuro. Assim, ao fixar o Outro numa imagem pitoresca que o desfigura, a escritora coloca-se numa situação de controle e poder que a protege frente ao desconhecido.

Nesse sentido, o indiano é apresentado como um ser sem qualquer tipo de conhecimento científico, já que para os ingleses os seus métodos de controle sobre a natureza, como no caso das enchentes do Hindus, são irracionais. Por sua vez, o narrador é um funcionário do governo, que todo ano vem, com seu conhecimento onipotente, tentar controlar até os rios da Índia a serviço da coroa britânica:

Pois ano após ano, armado da majestade da lei e escudado por réguas e mapas, o Governo da Índia, na pessoa de um de seus oficiais, vinha gravemente e alterava as proporções de terra e água na superfície do globo, enquanto o rio gorgolejava e formava covinhas, como se risse furtivamente $(50)^{11}$.

Se a ameaça que os indianos representam para os ingleses pode ser diluída quando apresentada sob a perspectiva do exótico, também a violência do projeto colonizador fica disfarçada quando o desejo de possuir e controlar está encoberto pelas descrições de caráter pitorescas do rio e da natureza.

Porém, aquilo que se tenta reprimir vem à superficie nas entrelinhas da narrativa: "Mas a implacável corrente de ferro seria reclamada, e um outro trecho verde seria marcado no mapa de impostos, pois Governos ignoram o acaso. Ainda assim ela formava covinhas e gorgolejava com uma alegria interior; pois se deu a ervilhaca, não havia tirado o trigo?" (52) ${ }^{12}$.

A paisagem pitoresca torna-se apenas uma outra possessão do Raj claramente marcada no "Atlas do Império", ao passo que o rio, com seu mistério, produz ou destrói colheitas e representa mais ou menos ingressos para o Raj. Uma vez mais, tudo se reduz ao projeto colonial de ocupar terras e recolher impostos.

\footnotetext{
11 "For year after year, armed by the majesty of law and bucklered by foot-rules and maps, the Government of India, in the person of one of its officers, came gravely and altered the proportions of land and water on the surface of the globe, while the river gurgled and dimpled as if it were laughing in its sleeve"

12 "But the ruthless iron chain would come into requisition, and another green spot be daubed on the revenue map, for Governments ignore chance. And still dimpled and gurgled with inward mirth; for if it gave the vetch, had it not taken the wheat?'
} 
Segundo tentamos demonstrar através da leitura de "Lâl", e voltando ao questionamento de Suleri sobre o lugar das narrativas femininas no projeto colonial, podemos dizer que elas evidentemente têm o valor de suplemento como plenitude e não aditivo, já que mais que estilizar o discurso hegemônico masculino, o desenvolvem revelando a consciência da mulher sobre os objetivos dos ingleses na Índia. Lido dessa perspectiva, "Lâl" é uma metáfora, altamente ideologizada, sobre a confronto entre dois estilos de vida suficientemente diferentes para impedir qualquer tipo de compreensão mútua. Isso colocaria a estória de Steel não na periferia do pitoresco mas no centro do projeto histórico colonial.

\section{II.2 "Ann White": Entre a história e a ficção}

As escritoras do Raj também adentraram o discurso da história sob a forma de anedotas, representações de eventos de caráter histórico na forma de estórias curtas. Conforme Sara Suleri, as mulheres nas colônias transformavam ".... a história em contos ou fábulas. Assim, ao se utilizar dos termos "compassivos" da anedota, reduziam a violência da história ao mesmo tempo que evitavam examinar as implicâncias simbólicas dessas vinhetas ${ }^{13}$ " (1992:100)

Segundo nossa leitura, se por um lado as escritoras do Raj se utilizaram da anedota para narrativizar a história, como uma das formas aparentemente inocentes de narrar, por outro, o tom e os eventos narrados ultrapassam claramente os limites do gênero. Uma vez mais, essas estratégias mostrariam o desejo de se rebelar contra o locus de enunciação que lhes é imposto, já que entendemos que há nessas estórias um desejo implícito das autoras de participar do projeto de interpretação da história, “.... a fim de que se possa emergir, não apenas a história de dominação masculina, mas sobretudo os papéis informais, as improvisações, a resistência da mulher" (Silva Dias 1994:274). Dessa maneira, a escrita feminina quebraria furtivamente o cerco que lhe é imposto para se colocar, uma vez mais, no centro do projeto histórico colonial.

Um dos eventos históricos mais narrados da Anglo-Índia tem sido o Amotinamento de 1857 que, como explica Suleri, foi o epítome da violência do confronto colonial no século XIX. Se para os indianos esse evento representou um dos primeiros movimentos de rebelião contra a presença inglesa na Índia, para

${ }^{13}$ Nossa tradução. 
os ingleses ele foi visto como uma conspiração que confirmava a barbárie dos indianos, já tantas vezes representada nos textos dos Orientalistas ${ }^{14}$, o que, por sua vez, justificava a presença inglesa na Índia como parte da missão civilizadora.

Assim, o Amotinamento tornou-se não só um dos temas principais da narrativa histórica inglesa na Índia mas também motivo de uma literatura melodramática que encontrou inspiração nas atrocidades perpetradas nos sangrentos eventos. Como assinala Patrick Brantlinger em seu livro Rules of Darkness, nenhum outro episódio da história imperial britânica teve tanta repercussão nem produziu tantos artigos de jornais e narrativas históricas e ficcionais como o Amotinamento de 1857 (1988:199).

Muitas dessas narrativas foram escritas por mulheres, ainda que tempos depois do Amotinamento, com o objetivo não só de relembrar os fatos, mas porque o temor de um novo levante estava sempre presente. Tal é o caso do conto "Ann White" de Alice Perrin.

O público alvo dessa escritora, conforme Benita Parry, eram os ingleses back home, bem como os anglo-indianos. Seus livros mais conhecidos são duas coleções de contos, East of Suez (1901) e Red Records (1906), que apresentam

110 mistérios, horrores e uma obsessão pela morte violenta e desastres sinistros.

Em "Ann White" a memória de 1857 é recriada através da figura fantasmagórica de uma velha mulher, sobrevivente do Amotinamento, cuja mente, ainda na sua velhice, está fixada nesses eventos, sobretudo no momento em que ela foi deixada na floresta, vestida com roupas nativas como um último gesto de desespero da sua mãe para salvar sua vida. Desde então, ela representa para a

\footnotetext{
${ }^{14}$ Segundo Patrick Brantlinger em Rules of Darkness (1988), "A causa imediata da rebelião foi munição para os rifles Enfield; os soldados do exército bengalês suspeitavam que os cartuchos haviam sido untados com gordura de vaca e porco. As pontas de papel tinham que ser arrancadas com a boca antes de ser usadas, e uma vez que gordura de vaca era tabu para os hindus e gordura de porco para os muçulmanos, os britânicos pareciam estar forçando os dois grupos de soldados a cometer um sacrilégio. Havia, é claro, causas mais importantes - Disraeli disse no Parlamento que 'a ascenção e queda dos impérios não são uma questão de cartuchos untados' - mas a maioria dos analistas britânicos encontraram insatisfação somente entre os regimentos de nativos, o que os poupou de admitir uma agitação generalizada. Entre os historiadores britânicos e indianos, o debate ainda se dá sobre se o levante foi apenas um 'motim' militar, ou uma 'rebelião civil', bem como, ou como nacionalistas indianos sustentaram, 'a primeira guerra de independência da Índia" (200-201) (nossa tradução).
} 
comunidade a memória viva da rebelião indiana, bem como o temor de que algo do mesmo tipo possa voltar a acontecer.

A narradora começa o relato num cemitério na Inglaterra, que ela descreve como um local pacífico e fresco, o qual é, indireta e implicitamente, comparado ao calor e ao pó (heat and dust) que os ingleses associam à Índia: "pessoas que moraram no Oriente sentem o calor mais fortemente do que os que nunca experimentaram meses a fio de dias e noites sufocantes, céus metálicos implacáveis, o clarão branco de um sol mortal" $(190)^{15}$.

Numa outra passagem, o cemitério inglês é descrito quase que como um paraíso verde com flores e abelhas, quando comparado com os cemitérios indianos, nos quais os ingleses, apresentados como vitimas do exílio, são esquecidos:

Quando eu olhei ao meu redor eu pensei: que contraste com os cemitérios áridos que eu havia visto na Índia, com seus memoriais descuidados das vítimas do exílio, todas as inscrições trágicas que falavam de mortes prematuras; mulheres e crianças que na Inglaterra poderiam ter se recuperado de doenças, homens ceifados em sua juventude, ou quando a tão aguardada aposentadoria se aproximava; às vezes famílias inteiras varridas pelo cólera $(191)^{16}$.

O que primeiro parece chamar atenção do leitor é o fato de que esses mortos, segundo a narradora, são vitimas da Índia e não do projeto de conquista colonial. A presença inglesa no subcontinente nunca é questionada, o que indiretamente mostra o posicionamento ideológico da narradora.

Nesse momento, o túmulo de uma mulher chamada Ann White, lembra a narradora de um outro túmulo, também de uma mulher, chamada Ann White na Índia. Revelando o caráter misterioso da estória, que denota as convenções da literatura romântica vitoriana, a narradora entra num estado de vigília e

15 "...people who have lived in the East feel the heat more severely than those who have never experienced months on end of stifling days and nights, pitiless metallic skies, the white glare of a death-dealing sun."

16 "As I glanced about me I thought what a contrast to the arid cemeteries I had seen in India, with their neglected memorial to victims of exile, all the tragic inscriptions that told of untimely deaths; women and children who in England might have recovered from sickness, men cut off in their youth, or when long-looked-for retirement was in sight; sometimes whole families swept off by cholera". 
começa a relembrar uma "história" (não “estória”) acontecida na Índia há muito tempo: "Inebriado pelo perfume quente e a paz, eu deixei a história daquela outra Ann White adentrar minha cabeça, lentamente, vagamente" (192) ${ }^{17}$. Já desde o começo, a narradora, leal ao Raj (como a autora mesma do conto), marca as diferenças entre o olhar masculino e feminino na Índia. Ela lembra a primeira vez que se encontrou com Ann White:

A primeira vez que a vi foi no começo da estação quente, logo após eu ter chegado à Índia para cuidar da casa do meu irmão. Ela estava sentada, com uma aia de aparência descuidada, agachada ao lado dela, na beira do antigo coreto de concreto que ainda permanecia em uma das extremidades da abandonada quadra de desfiles. [...] Eu me lembro de ter comentado com meu irmão, quando passávamos pelo coreto, que era realmente incomum ver uma inglesa daquela idade vivendo na Índia - quem era ela? E Tom disse, indiferente, que não sabia; ele acreditava haver uma lenda sobre a velha senhora, mas não conseguia lembrá-la. Que importância tinha isso? (192) ${ }^{18}$.

O irmão da narradora, como oficial do Raj, ocupa-se, em todo caso, em fazer a história e não com fantasias. Mas ela, reconhecendo o espaço textual designado à mulher, e constituindo-se em sujeito narrativo a partir dele, imediatamente sente-se atraída pela estória e quer desvendar o mistério. Porém, é a partir dessa lenda que ela irá reconstruir um evento histórico, no qual Ann White, a velha mulher com sua mente suspensa no tempo, funcionará como a memória viva do Motim:

\footnotetext{
17 "Drowsed by the warm perfume and peace, I let the history of that other Ann White steal through my mind slowly, dreamily."

18 "The first time I saw her was at the beginning of the hot weather, soon after I had arrived in India to keep house for my brother. She was seated, with an untidy-looking ayah, squatting beside her, on the edge of the old concrete bandstand that still remained at one end of the deserted parade-ground. [...] I remember remarking to my brother as we rode past the bandstand, that it was surely unusual to see an Englishwoman of that age living in India - who was she? And Tom said indifferently, he didn't know; he believed there was some legend about the old lady, but he couldn't remember. What did it matter?"
} 
Tendo uma disposição imaginativa ou, mais precisamente, inquisitiva, eu senti um desejo de investigar a história da velha senhora. O que ela estaria fazendo na Índia naquele período da vida, e parecendo um fantasma do passado, vestindo um gorro e um vestido cinza vultoso? Ela quase poderia estar vestindo uma saia-balão. Deve ter sido uma história interessante $(193)^{19}$.

É interessante notar que, se num primeiro momento ela se define a partir do olhar masculino, descrevendo-se como uma pessoa de natureza imaginativa, o que seria considerado como uma característica naturalmente feminina, no entanto ela imediatamente parece se rebelar contra a possibilidade de ser categorizada dessa maneira e se redefine como inquisitiva. Enquanto o primeiro termo estaria associado com a literatura de caráter fantasioso e, por isso, feminino, o segundo pertenceria ao terreno da pesquisa histórica, considerado como masculino.

Assim, estes sutis traços mostram como as fronteiras entre a história e a estória parecem sub-repticiamente se apagar em "Ann White". Aliás, embora tentando narrar os fatos de maneira neutra e com ênfase nos seus aspectos mais espetaculares e fantasiosos, a narradora mostra não ser indiferente a sua significância histórica e indiretamente tenta justificar a maneira de agir dos ingleses culpando, de uma maneira velada, os missionários com os quais Ann White morava pela rebelião indiana.

Segundo Brantlinger, antes do Amotinamento de 1857 os ingleses pensavam que a catequização dos missionários ajudaria a converter os indianos do barbarismo ao modo de vida ocidental e, em particular, britânico (1988:200). Mas, depois do levante os ingleses se mostravam céticos com respeito ao trabalho dos missionários, já que achavam que mais do que ajudar o Raj, estes indispunham os nativos contra eles, porque ao tentar impor o cristianismo, atacavam as religiões locais ${ }^{20}$.

19 "Being of an imaginative, or, perhaps, more truthfully, an inquisitive disposition, I felt a longing to ferret out the old lady's history. What was she doing in India at her time of life, and looking like a ghost from the past, dressed in a poke bonnet and a voluminous greygown? She might almost have been wearing a crinoline. There must have been some interesting story".

${ }^{20}$ No seu romance The Devil's Wind. Nana Saheb's Story (New York: The Viking Press, 1972) o escritor indiano Manohar Malgonkar narra o Amotinamento de 1857 da perspectiva indiana. A estória/história é narrada para os ingleses por Nana Saheb, uma persona- 
Ciente desse conflito, Perrin faz uma digressão indo da narrativa ficcional para a narrativa da história, e assim cruzando as barreiras do gênero, problematiza a questão dos missionários na Índia e os mostra através de duas perspectivas: a da colônia inglesa residente no subcontinente e a dela própria, uma recém chegada:

As outras senhoras da missão me asseguraram que quando eu estivesse morando há muito tempo na Índia eu entenderia que o ardor de missionários como o Senhor Grigson fazia mais bem que mal, interferindo em crenças antigas que convinham ao povo, enchendo garrafas velhas com vinho novo, freqüentemente criando problema nos bazares onde problemas o bastante já estavam se armando. Aqui em Jutpore, por exemplo, era bem sabido que existia um sentimento forte contra a influência da missão. Qualquer coisa a qualquer momento poderia levar a uma revolta; os missionários seriam os primeiros a sofrer se a multidão ficasse fora de controle, e então provavelmente nós todos teríamos nossas gargantas cortadas $(198)^{21}$.

Porém, por meio de sua narradora, Perrin oferece uma perspectiva diferente sobre o trabalho dos missionários no sentido de que, embora nem sempre eficazmente, o seu propósito seria resgatar os indianos de sua "ignorância".

gem mais cruel do que Napoleão, para os indianos o primeiro líder no caminho à independência. Ele explica que o incidente dos cartuchos com gordura de porco e vaca era entendido pelos indianos como uma manobra, por parte dos ingleses, de conversão massiva ao cristianismo: "O rumor de que os britânicos estariam tramando uma conversão em massa do exército por meio dos novos cartuchos havia se espalhado com a velocidade de uma brisa de monsão"(105). Também, “Agora a Companhia [da Índia Oriental] estava tentando uma conversão em massa das cidades adulterando farinha de trigo com sangue e ossos de vacas e porcos. Os portugueses não haviam feito o mesmo em Goa - convertido vilarejos inteiros jogando carne bovina dentro dos poços comunitários? Esses eram os dispositivos reconhecidos do proselitismo" (133) (nossa tradução).

21 "The other ladies in the mission assured me that when I had lived long in India I should realize that the ardour of missionaries like Mr Grigson did more harm than good, interfering with ancient faiths that suited the people, forcing new wine into old bottles, often making trouble in the bazaars where already trouble enough was brewing. Here in Jutpore, for example, it was well known that a strong feeling existed against mission influence. Anything at any moment might lead to a riot, the missionaries would be the first to suffer if the mob got out of hand, and then probably we should all have our throats cut". 
Eu passei a entender e apreciar seus esforços, a compartilhar sua convicção de que embora o trabalho pudesse parecer apenas um arranhão na superfície da idolatria, ele valia a pena infinitamente, e deveria no final levar a uma profunda diminuição da ignorância e da superstição de um povo mergulhado na adoração à Natureza, oprimido cruelmente por castas superiores, o sacerdócio, e indiretamente por ele mesmo $(197)^{22}$.

A idéia de não confiar na missão civilizatória dos missionários teria a ver com o fato de que depois do Amotinamento os ingleses pensavam que a Índia nunca progrediria. Como aponta Brantlinger, depois do Amotinamento, e sob uma perspectiva claramente etnocêntrica, a Índia é apresentada como irremediavelmente imersa em superstição e violência (1988:200). Esta é justamente a idéia que Perrin parece estar transmitindo sobre a Índia na sua estória: uma cultura onde a violência e a morte, como havia mostrado o Amotinamento, nunca seriam erradicados, já que mais do que serem produzidos pela ação dos ingleses eles eram o resultado de alguma qualidade própria dos indianos, o que vem demonstrar o posicionamento ideológico da escritora. Porém, como também assinala Brantlinger, os ingleses reagiram à violência dos indianos com mais violência, embora esses fatos nunca apareçam em "Ann White".

Segundo nossa leitura, o relato de Perrin vai além do pitoresco e o anedótico ao se posicionar com a relação um tema histórico controvertido. Por meio do sentimental e do imaginativo, ferramentas literárias femininas, a narrativa, marcadamente ideológica, rescreve a história oficial do Amotinamento de 1857 mas, ao mesmo tempo, revela a atmosfera de temor e morte na qual as famílias inglesas residentes no subcontinente permanentemente vivem, revelando o lado escuro da conquista imperial. É o discurso da ficção a serviço do discurso da história.

\section{II.3 “Uma mãe na Índia”: A Hermenêutica do Quotidiano}

Segundo Suleri, a grande pergunta com a qual o leitor se defronta na leitura dos textos das memsahibs é “...até que ponto a mulher britânica esta envolvida

\footnotetext{
22 "I grew to appreciate understand and appreciate their efforts, to share their conviction that though the work might seem but a scratch on the surface of idolatry, it was infinitely worth while, and must lead eventually to a deep undermining of ignorance and superstition among a people steeped in Nature worship, cruelly oppressed by higher castes, the priesthood, and indirectly by each other".
} 
na estrutura do colonialismo, e que fronteira pode ser traçada entre sua conivência e seu confinamento na colonização do subcontinente ${ }^{23 "}$ (1992:76). Entendemos que a resposta que Suleri dá a essa pergunta é que a mulher inglesa está duplamente confinada, geograficamente no espaço colonial, como apontado anteriormente, e textualmente por meio do discurso restritivo do belo e do pitoresco.

Elas são cativas de um sistema colonial de governo que impõe o seu deslocamento geográfico para a Índia com o intuito de usá-las como barreira entre o homem inglês e a mulher indiana, entendida essa última como a grande ameaça à pureza da raça branca.

Como as indianas, as inglesas também personificam a sua tradição: "A mulher anglo-indiana estava na Índia como símbolo do lar inglês; ela era a personificação de tudo o que o inglês deve proteger. Ela era uma salvaguarda contra os perigos apresentados pela mulher oriental ${ }^{24 "}$ (Suleri 1992: 76). Porém, comparada à mulher inglesa, a mulher indiana, que também devido ao duro sistema patriarcal vive confinada na zenana ${ }^{25}$, é paradoxalmente mais independente. Como explica Suleri, isto deve-se ao fato de que os filhos das mulheres indianas fazem parte da sua vida, enquanto a mulher inglesa tem

116 que se separar muito cedo de seus filhos quando estes são enviados para estudar na Inglaterra a fim de conservar a pureza da raça e da cultura. Tudo isso vem mostrar que as arrogantes memsahibs, como as mulheres inglesas têm sido muitas vezes representadas, são também vítimas da violência de um sistema colonial que produz uma crise na estrutura familiar ao provocar seu deslocamento da Inglaterra para outro local do império. Então, embora o gênero do pitoresco tente restringir o poder de expressão da mulher anglo-indiana, a literatura, como terceiro espaço, é uma das saídas que essa mulher tem para escapar dos papéis normativos que lhe são impostos.

Um dos contos mais refinados da tradição Anglo-Indiana que narra a separação traumática entre mães e filhos é "Uma mãe na Índia" (1903) escrito, como já apontado, não por uma escritora inglesa mas por uma canadense, Sara Jeannette Duncan (1861-1922), que emigrou para a Índia aos trinta anos com seu marido, curador do Museu de Calcuttá, e passou o resto de sua vida entre

\footnotetext{
${ }^{23}$ Nossa tradução.

${ }^{24}$ Nossa tradução.

${ }^{25}$ Área de uma casa indiana onde as mulheres da familia vivem em reclusão.
} 
o subcontinente e a Inglaterra, voltando só esporadicamente para o Canadá. Porém, o fato de ser originariamente do Canadá, colônia não de conquista mas de assentamento (Ashcroft et al 1996), onde os colonos eram e se sentiam bran$\cos$, faz de Duncan parte da elite imperial e, portanto, a coloca em uma situação de superioridade em relação aos indianos. Ao mesmo tempo, o posicionamento de Duncan faz de sua narrativa um testemunho de relevância, já que ela está, ao mesmo tempo, por dentro e por fora do conflito colonial na Índia. No primeiro caso porque devido a sua nacionalidade, ela pôde olhar a relação entre ingleses e indianos em perspectiva, de uma maneira crítica e, no segundo caso, porque como membro do Commonwealth Britânco, ela fez parte da colônia inglesa na Índia. Como as mulheres residentes nessa comunidade, ela mesma, como explica Teresa Hubel, foi vítima do conflito gerado pelo fato de fazer parte do aparato imperial além de ser uma mulher que criticava o sistema patriarcal (1996: 47).

Nessa perspectiva, Duncan escreveu três romances: The Simple Adventures of a Memsahib (1893), His Honour and a Lady (1896) e The Burnt Offering (1909), assim como quatro contos publicados com o título The Pool in the Desert (1903), dentre os quais está "Uma mãe na Índia".

A partir do foco feminino, entendemos que o propósito de Duncan seria recriar a relação entre Índia e Inglaterra por meio de metáforas familiares. A primeira metáfora lida com a relação entre mães e filhos e a segunda, com o casamento entre ingleses e, nesse conto em particular, os anglo-indianos.

Em "Uma mãe na Índia” Duncan, no que Suleri chama de "irônico tom de decoro", mostra a violência silenciosa perpetrada pelo sistema colonial na relação entre uma mãe e sua pequena filha quando esta é levada a Londres e é criada por sua avó e tias, segundo os padrões da Inglaterra do século XIX; quando volta para se reunir com sua mãe na Índia, ambas são perfeitas estranhas.

Devido às doenças que constantemente ameaçam os ingleses na Índia, quando a criança tem um mês de vida é levada para a Inglaterra porque corre risco de morte, produzindo-se assim a separação de sua mãe:

Ela tinha apenas cinco semanas de vida quando o médico nos disse que deveríamos levá-la para casa imediatamente ou a perderíamos, e no dia seguinte John pegou uma disenteria. Então Cecily foi enviada para a Inglaterra com a mulher de um sargento que havia perdido seus gêmeos, e eu me coloquei sob a orientação de um médico nativo para lutar pela vida do meu marido, sem gelo ou comida adequada, ou um 
leito ou conforto de qualquer espécie. Ah! O Forte Samila com o sol resplandecendo na areia! $(75)^{26}$.

O que se lê por atrás do tom de eqüidade da narrativa é uma história de doença, morte e sacrifício num lugar totalmente longínquo e alheio. A narradora não só tem que se separar de sua pequena filha mas, ainda convalescente do parto, tem que cuidar de seu marido doente em condições de grande precariedade. Entendemos, então, que embora livre de qualquer tipo de sentimentalismo, a grande história, mais do que estória, sendo narrada além do característico da vida de Anglo-Índia, é a do grande sacrifício realizado pelos súditos ingleses pela grandeza do Raj, principalmente e num tom paradoxalmente amortecido, a história da impotência da mulher inglesa presa ao sistema colonial.

Assim a narradora conta como a mãe e irmãs do marido, mulheres de grande gentileza (gentility) embora de recursos limitados, a informam sobre a educação de sua filha nas cartas semanais que ela, por sua vez, lê escondendo sua raiva ou frustração atrás de uma pretensa tranqüilidade que, como discute Suleri, tem mais de histeria do que de calma:

Enquanto isso nós notávamos o progresso semanal com muito do sentimento que se teria por um pedacinho longínquo de prosperidade que não dava nenhum trabalho e se saía extremamente bem. Nós teríamos a custódia de Cecily ao nosso dispor; até lá, era gratificante saber que havíamos conquistado um realce em suas covinhas e em seus doces cachinhos $(77)^{27}$.

Quando finalmente a mãe tem a possibilidade de viajar para a Inglaterra não é para ver sua filha, mas acompanhar o marido que foi promovido, fato

\footnotetext{
26 "She was just five weeks old when the doctor told us that we must either pack her home immediately or lose her, and the very next day John went down with enteric. So Cecily was sent to England with a sergeant's wife who had lost her twins, and I settled down under the direction of a native doctor, to fight for my husband's life, without ice or proper food, or sick-room or comforts of any sort. Ah! Fort Samila with the sun glaring up from the sand!".

27 "Meanwhile we noted the weekly progress with much the feeling one would have about a far-away little bit of property that was giving no trouble and coming on exceedingly well. We would take possession of Cecily at our convenience; till then, it was gratifying to hear of our earned increment in her little dimples and sweet little curls" (77)".
} 
esse também narrado de maneira monotônica e casual. À medida em que o momento do encontro entre mãe e filha se aproxima, o ritmo da narrativa vai num crescendo mas, ao invés de terminar num clímax de afetuoso reconhecimento, se resolve numa situação altamente anticlimática, quando a filha, como previsto, trata a mãe como uma perfeita desconhecida:

Ela veio a meio caminho; suponho que nossos olhares foram muito fixos, absortos demais, pois lá ela parou com um grito de terror diante dos rostos estranhos, e voltou correndo para os braços abertos de sua tia Emma. A coisa mais natural do mundo, sem dúvida. Eu caminhei até uma cadeira em frente com minha bolsa e guarda-chuva e me sentei - uma espectadora, distante e silenciosa [...] Não é divertido até agora lembrar a raiva que eu senti. Eu não a toquei nem falei com ela; eu simplesmente fiquei sentada observando minha posse alheia, com o vestido que eu não havia feito e a faixa que eu não havia escolhido, sendo induzida e protegida e afagada por tia Emma (78-79) ${ }^{28}$.

Há em "Uma mãe na Índia" uma desfamiliarização do tema da maternidade produzida justamente pela separação que faz com que mãe e filha se sintam duas estranhas. Porém, a ruptura não é somente geográfica mas também cultural. Segundo Suleri, as narrativas dessas muheres mostram “...a ambivalência produzida pela decentralização da vida doméstica da Anglo- Índia” desde que seus filhos vão se afiliar a uma ou outra cultura (1992: 98). Na maioria das vezes as mães, segundo mostra Duncan, não podiam imprimir um rumo determinado às histórias dos seus próprios filhos já que eles se encontravam culturalmente separados, o que produzia uma terrível frustração ao mesmo tempo que demonstrava a impossibilidade de a mulher na colônia controlar sua própria família.

Embora durante sua residência na Índia os britânicos continuassem considerando a Inglaterra como home, de volta à Europa após anos de serviço

\footnotetext{
28 "Half-way she came; I suppose our regards were too fixed, too absorbed, for there she stopped with a wail of terror at the strange faces, and ran straight back to the outstretched arms of her Aunt Emma. The most natural thing in the world, no doubt. I walked over to a chair opposite with my hand-bag and umbrella and sat down - a spectator, aloof and silent $[\ldots]$ It is not amusing even now to remember the anger I felt. I did not touch her or speak to her; I simply sat observing my alien possession, in the frock I had not made and the sash I had not chosen, being coaxed and kissed and protected and petted by Aunt Emma".
} 
eles se tornavam estrangeiros no seu próprio país. Duncan discute esse aspecto dos coloniais quando, a bordo do navio que volta para a Índia, depois da sua estadia na Inglaterra, a narradora reflete que:

Era um navio de Bombaim, cheio de anglo-indianos retornando. Eu olhei de um lado para outro as longas mesas do salão com um senso de alívio e consolo; eu estava de novo com o meu próprio povo. Eles pertenciam a Bengala e a Burma, a Madras e ao Punjab, mas eles eram todos o meu povo. Eu podia distinguir uma vintena que eu conhecia de fato, e não havia nenhum que em minha imaginação eu não conhecesse $(83)^{29}$.

O momento de ruptura cultural está marcado pelo novo apelo nacional "anglo-indiano". Assim, a narradora mostra como a experiência colonial a coloca num "terceiro espaço" que a torna uma estrangeira na sua própria cultura. Ela mesma é uma curiosidade para os ingleses.

Em sua próxima viagem à Inglaterra, mãe e filha se olham através das duas margens de um abismo cultural: "Nós passamos um verão agradável com uma garotinha numa casa cujo interesse por nós era engraçado, e cujos passeios era gratificante organizar; mas quando nós voltamos, eu não tive o desejo de levá-la conosco. Eu achei que ela estava muito melhor onde estava" $(81)^{30}$.

Uma vez mais de volta à Índia, a mãe se movimenta com o regimento de seu marido: "Nós volltamos para a fronteira e o regimento viu muito serviço. Isso significava medalhas e divertimento para meu marido, mas economia e ansiedade para mim, embora eu conseguisse ter a permissão de chegar tão perto da linha de fogo quanto qualquer mulher" $(80)^{31}$. Que estória/história está sendo

\footnotetext{
29 "It was a Bombay ship, full of returning Anglo-Indians. I looked up and down the long saloon tables with a sense of relief and solace; I was again with my own people. They belonged to Bengal and to Burma, to Madras and to the Punjab, but they were all my people. I could pick out a score that I knew in fact, and there were none in imagination that I didn't know".

30 "We spent a pleasant summer with a little girl in the house whose interest in us was amusing, and whose outings it was gratifying to arrange; but when we went back, I had not desire to take her with us. I thought her very much better where she was(81)"

31 "We went back to the frontier and the regiment saw a lot of service. That meant medals and fun for my husband, but economy and anxiety for me, though I managed to be allowed as close to the firing line as any woman" (80).
} 
contada? O mundo do marido pertence, como diria a autora indiana Arundhati Roy em O deus das pequenas coisas (1997), ao "deus das grandes coisas", das grandes causas e acontecimentos, dos eventos históricos que faziam parte do mundo masculino do Raj. O dela, porém, só traz frustração e ansiedade e uma eterna espera. As mulheres pertencem "ao deus das pequenas coisas", mas suas histórias/estórias também precisam ser contadas, embora relegadas ao mundo feminino do pitoresco.

Identificamos na narrativa de Duncan duas formações discursivas históricas: uma que narra a história oficial do Raj, a vida do colonizador inglês na fronteira do mundo civilizado, acompanhado pela sua mulher que representa os valores culturais ingleses, e outra na qual, embora a mulher sinta-se identificada com a Anglo-Índia, critica veladamente o sistema colonial que tem provocado uma ruptura familiar.

Segundo Teresa Hubel, em seu estudo sobre a obra de Duncan, a relevância dessas narrativas estaria na possibilidade de enxergar a Índia a partir de uma perspectiva feminina mostrando a sua surda resistência ao sistema patriarcal e implicitamente afirmando que, para muitas mulheres inglesas na Índia, a narrativa masculina não é apropriada, já que não reflete a sua realidade doméstica (1996:53).

A segunda metáfora da qual se utiliza Duncan para recriar a relação entre Índia e Inglaterra, além da que retrata a relação entre mães e filhas, é a do casamento. Segundo Hubel, a relação colonial entre Índia e Inglaterra poderia ser entendida como uma "relação conjugal" (1996: 47), que é também funcional em "Uma mãe na Índia”. Assim, o caráter alegórico do conto, no seu desejo de relatar não só a história das famílias mas também as diferenças culturais entre ingleses e anglo-indianos, alcança o seu clímax quando a filha, a pequena Cecily, cresce e, como era costume, vai com a mãe para Índia para se casar. A mãe acha irritante os "modos ingleses" (English manners) da filha, o que num outro nível vem mostrar em qual perspectiva, após morar alguns anos fora de seu país, os anglo-indianos viam os ingleses.

Já no navio para a Índia, Cecily, tanto na maneira de se comportar como nas roupas que veste, diferencia-se das mulheres e homens da Anglo-Índia que, após permanecerem anos longe da Inglaterra, se vestem e se comportam de uma maneira mais simples e diferente. A mãe narra como os anglo-indianos são reprovados pela filha porque sua aparência mostra que eles já não são ingleses puros mas "viraram nativos" (have gone native):

Cecily olhou para eles de soslaio. Para ela a atmosfera era estranha, e eu percebi que de modo delicado e privado ela registrava suas objeções 
(...) Ela olhava com um lábio crispado para as mulheres que andavam no convés com passos firmes, vestindo saias curtas e um tanto surradas, com as mãos nos bolsos de seus casacos falando de transferências e promoções; e tendo se levantado às seis para fazer um esboço em aquarela do nascer-do-sol, ela veio até a mim com uma profunda indignação para dizer que tinha visto um homem de pijamas; sem dúvida, pobre coitado, indo se barbear. Eu fui incapaz de convencê-la de que não se esperava que ele fosse vestido encontrar o barbeiro $(84)^{32}$.

Ao mesmo tempo, Cecily é vista por uma das mulheres a bordo como o perfeito retrato da Inglaterra:

'Eu acho', retomou a Senhora Morgan, cujo olhar havia vagado na mesma direção, 'que Cecily é um belo exemplo das nossas moças inglesas. Com aqueles olhos cinza-escuros, talvez um pouco proeminentes, e aquela boa cor - está um pouco forte agora, talvez, mas ela irá perdêla o bastante na Índia - e aqueles traços regulares, ela faria uma esplêndida Britannia' (92) ${ }^{33}$.

Cecily é caracterizada, na perspectiva irônica e crítica de sua mãe, como compartilhando a cegueira cultural dos ingleses pela sua inabilidade de ver além dos limites de sua cultura: "Você não parece ver que a moça é protegida por suas limitações, como uma tartaruga. Ela vive dentro delas bem segura, feliz e satisfeita" $(98)^{34}$. Seu interlocutor é um jovem inglês, residente na Índia, Dacres Tottenham, que, inexplicavelmente para a mãe, sente-se atraído por

\footnotetext{
32 "Cecily looked at them in askance. To her the atmosphere was alien, and I perceived that gently and privately she registered objections (...) She looked with a straightened lip at the crisply stepping women who walked the deck in short and rather shabby skirts with their hands in their jacket-pockets talking transfers and promotions; and having got up at six to make a water-colour sketch of the sunrise, she came to me in profound indignation to say that she had met a man in pyjamas; no doubt pour wretch, on his way to be shaved. I was unable to convince her that he was not expected to visit the barber in his clothes".

33 'I think', resumed Mrs Morgan, whose glance had wandered in the same direction, 'that Cecily is a very fine type of our English girls. With those dark grey eyes, a little prominent possibly, and that good colour - it is rather high now perhaps, but she will lose quite enough of it in India - and those regular features, she would make a splendid Britannia.'

34 "You don't seem to see that the girl is protected by her limitations, like a tortoise. She lives within them quite secure and happy and content."
} 
Cecily. Segundo ele, a moça tem a capacidade de ver a beleza em todas as partes: "Ela responde instantaneamente, intimamente, ao belo em toda a parte" ${ }^{35}$. Mas, como a mãe sugere, é o tipo do beleza que os ingleses enxergam: "Eu sei - o que você quer dizer com pores-do-sol. Cecily gosta muito de poresdo-sol. Ela está sempre me pedindo para vir e observá-los" $(101)^{36}$. Na sua caracterização de Cecily, Duncan antecipa a crítica que anos mais tarde E. M. Forster faria dos ingleses em A Room with a View (1908). Eles saem pelo mundo com seus padrões estéticos e seus guias de turismo Baedeker esperando ver as "vistas" que a sua própria cultura prescreve. Porém, eles não têm a capacidade, nem intelectual nem emocional, de enxergar o que outras culturas oferecem. Então eles voltam para Inglaterra sem ter se deixado influenciar pela cultura do Outro. É justamente dessa maneira que "Uma mãe na Índia” se resolve, mostrando como a ficção recria a cegueira dos ingleses no momento histórico do auge de seu império.

Quando Dacres Tottenham decide pedir Cecily em casamento, eles estão em Agra, a caminho de visitar o Taj Mahal junto com a mãe que, ao narrar a reação de Cecily a tudo o que vê, a recria como o estereótipo dos "English abroad" de Forster:

[Cecily] falava sem parar, apontava isso e aquilo, e perguntava quem morava aqui e quem morava acolá. Em intervalos regulares de quatro minutos ela perguntava se aquilo não era simplesmente lindo demais. Ela sentava-se ereta com seu perfil vigoroso e seu chapéu elegante; e a silhueta de sua personalidade se recusava a se misturar com a poeira da dinastia. Ela era um contraste; definitivamente ela era uma indignidade. "Recoste-se, minha querida", eu finalmente exclamei. "Você está atrapalhando a paisagem" $(111)^{37}$.

\footnotetext{
35 "She responds instantly, intimately, to the beautiful everywhere".

36 "I know - what you mean sunsets. Cecily is very fond of sunsets. She is always asking me to come and look at them."

37 "[Cecily] talked continually, she pointed out this and that, and asked who lived here and who lived there. At regular intervals of about four minutes she demanded if it wasn't simply too lovely. She sat straight up with her vigorous profile and her smart hat; and the silhouette of her personality sharply refused to mingle with the dust of the dynasty. She was a contrast, a protest; positively she was an indignity. "Do lean back, dear child', I exclaimed at last. "You interfere with the landscape."
} 
Cecily é caracterizada como mostrando um entusiasmo por tudo aquilo que ela enxerga, o que por sua vez denota o interesse dos ingleses pelo exótico, que logo se transforma nos escritos femininos do pitoresco. Ao mesmo tempo, o que a narrativa tenta sublinhar é que, por todo o seu entusiasmo, Cecily se nega a fazer parte dessa paisagem: ela se destaca e não se mistura.

Dacres e Cecily saem da carruagem e entram nos jardins do Taj Mahal enquanto a mãe fica pensando na história do Imperador Mughal que, num gesto póstumo de amor eterno, mandou construir o belo palácio em memória de sua amada. Embora a mãe acredite que a relação entre os dois jovens é quase impossível e ela mesma tenha tentado mostrar para Dacres as limitações da própria filha, nesse momento e local ela pensa que quiçá a união entre ambos fosse possível: quem poderia ser cego ou indiferente a tanta beleza? Mas quando os jovens rapidamente voltam para a carruagem, as palavras irônicas de Dacres - ironia a que Cecily permanece totalmente alheia - mostra a impossibilidade da união:

"Você não demorou", disse [a mãe]. 'Espero que você não tenha se apressado por minha causa" "A Senhorita Farnham achou o mármore um pouco frio sob seus pés", respondeu Dacres, incluindo a Senhorita Farnham.” "Sabe' explicou Cecily, 'Eu me esqueci tolamente de calçar um solado mais grosso. Eu estou só de sandálias. Mas, mamãe, como é lindo! Vamos voltar durante o dia. Eu estou louca para fazer um desenho" $(113)^{38}$.

Numa cena de dimensões fosterianas, Cecily é apresentada como totalmente insensível a uma das representações mais monumentais da cultura do Outro, a não ser pelo desejo de reduzi-la a um desenho para levar de volta para casa e demonstrar, como Lucy Honeychurch em Uma janela para o amor (A Room with a View), que ela soube "ver" aquilo que tinha de ser visto, enquanto que, por meio de ironia dramática, a narradora mostra que ela não podia enxergar nem o que estava acontecendo com a sua própria vida. Assim, é a rigidez de Cecily que vai levar Dacres a preferir se casar, ironicamente, com uma rica

\footnotetext{
38 "You have not been long", said [the mother]. 'I hope you didn't hurry on my account" 'Miss Farnham found the marble a little cold under foot", replied Dacres putting Miss Farnham in".

"You see', explained Cecily, 'I stupidly forgot to change into thicker soles. I have only my slippers. But, mamma, how lovely it is! Do let us come again in the daytime. I am dying to make a sketch of it."
} 
herdeira americana, enquanto Cecily lamentará em silêncio, como manda o decoro inglês, a perda do único homem que amará em toda sua vida.

Como aponta Teresa Hubel, Duncan nos faz pensar sobre "o quanto devemos acreditar nos ideais expressados na superifice do texto e o quanto devemos permitir que o subtexto os subverta" (47). Num outro nível, então, a estória parece dizer que o fato de a mãe de Cecily ter feito todo o possível para mostrar para Dacres as limitações de sua filha pode se re-significar como o desejo da narradora de que a Índia, ou a Anglo-Índia, personificada em Dacres, não se ajoelhe ou se deixe conquistar por uma Inglaterra tão convencida dos seus próprios valores, que nunca poderá enxergar o Outro senão como uma imagem apreendida em algum dos tantos textos escritos e desenhados sobre a Índia pelos mesmos ingleses.

Por outro lado, se a estória/história é reconsiderada pela perspectiva de Cecily, o que se lê nas entrelinhas é que a Inglaterra sempre lamentará o desencontro cultural com a Índia mas, como Cecily, nunca admitirá sua inabilidade para aceitar a cultura do Outro além dos limites do pitoresco.

Entendemos que narrativas como as de Sara Jeanette Duncan, uma vez mais, vão além do meramente anedótico, refletindo sobre um conflito social numa conjuntura histórica. Enquanto "Uma mãe na Índia” não parece exceder os limites de outro tableau vivant sobre os britânicos no acantonamento, a ironia que permeia o texto funciona como tropo de desconstrução do imaginativo e ficcional da estória para colocar a narrativa dentro do discurso da história. Embora nunca dito abertamente, o desejo de relatar indo além das fronteiras textuais impostas pelo discurso masculino mostra que as mulheres criam, por meio de sua literatura, um modo de resistência ao modelo imperial patriarcal, ao mesmo tempo que refletem sobre sua própria identidade e seu lugar nele.

Num outro nível, a narrativa de Duncan problematiza a idéia, proposta por escritores como E. M. Forster em Passagem para Índia (A Passage to India), de que as memsahibs foram uma das principais causas de desencontro entre indianos e ingleses. Se no cantonment moravam mulheres como Cecily, abnegadas porém cegas, também havia mulheres como a própria narradora, capazes de enxergar a complexidade da situação da mulher na Índia, assim como seus conflitos culturais. 


\section{Conclusão}

Entendemos que todas essas estórias não só historicizam a presença britânica na Índia mas, denunciando o seu caráter iterativo ao tentar reproduzir a perspectiva das narrativas imperiais, as transformam revelando o olhar da mulher não só sobre aquilo que narra mas sobre sua própria situação nessa estrutura colonial.

Que contam essas estórias? Revelando o olhar feminino, elas falam da relação entre colonizador e colonizado, das diferenças culturais que os separam, da ausência de interesse do europeu pelo Outro, do que há na consciência coletiva dos anglo-indianos, presos entre duas culturas e, particularmente, do confinamento da mulher e o seu desejo de subverter a ordem que lhe é imposta.

A história/estória nessas narrativas é contada de maneira oblíqua, a partir de seus detalhes que parecem ofuscar o corpus principal. Como tentamos demostrar, entendemos que isso é assim porque as mulheres na colônia têm consciência do seu locus de enunciação. É como se elas não quisessem se pronunciar em relação ao sistema imperial mas, o discurso as traísse. Por isso, quanto mais tentam ocultar a narrativa que se adivinha nos interstícios do texto, mais se insinuam e apagam os limites entre ficção e história.

\section{Referências Bibliográficas}

ASHCROFT, Bill et alli. The Empire Writes Back. London \& New York: Routledge, 1989.

BHABHA Homi. 'Freedom's Basis in the Indeterminate” In The Identity Question. London \& New York: Routledge, 1992. (47-61);

BAKHTIN, Michael. The Dialogic Imagination. Michael Holquist, ed. Caryl Emerson \& M.Holquist, trad. Austin: University of Texas Press, 1990.

BRANTLINGER, Patrick. "The Well at Canwpore: Literary Representations of The English Mutiny in 1857". In Rules of Darkness. British Literature and Imperialism, 1830-1914. Cornell University Press, 1988. (199-224).

BUTLER, Judith. "Fundamentos Contingentes: O Feminismo e a Questão do 'PósModernismo" " In Cadernos Pagu. (11) 1998:pp.11-42.

DERRIDA, Jacques. Acts of Literature. New York \& London: Routledge, 1992. 
DIAS, Maria Odila Leite da Silva. "Novas Subjetividades na Pesquisa Histórica Feminista: uma hermenêutica das diferenças" In Estudos Feministas. CIEC/ ECO/UFRJ Vol. 2 N 2/94.(373-382).

DUNCAN, Sara Jeannette. "A Mother in India” In Stories from the Raj. Saros Cowasjee, ed. London: Triad Panther, 1982. (74-118).

HUBEL, Teresa. "A Memsahib and Her Not-So-Simple Adventures" In Whose India? Durham \& London: Duke University Press, 1996. (45-70).

PARRY, Benita. Delusions and Discoveries. London: Allen Lane the Penguin Press, 1972.

PERRIN, Alice "Ann White". In Women Writers of the Raj. Saros Cowasjee, ed. London, Glasgow, Toronto, Sydney, Auckland: Grafton Books, 1990. (191-204). STEEL, Flora Annie. "Lâl". In More Stories from the Raj. Saros Cowasjee, ed. London, Glasgow, Toronto, Sydney, Auckland: Grafton Books, 1986. (51-59).

SOUZA, Lynn Mario T Menezes de. "O Rato que Ruge: O Discurso Críticoliterário pós-colonial como suplemento” In Crop No 1. nov.1994. DLM-USP. São Paulo. (60-66).

SULERI, Sara. "The Feminine Pictureseque" In The Rhetoric of English India. The University of Chicago Press, 1992.(75-110). 